\title{
Martin Brons
}

\section{Augustins Trinitätslehre praktisch: Katechese, Liturgie, Predigt}

\author{
Ritual und Unterweisung auf dem Weg zur Taufe
}

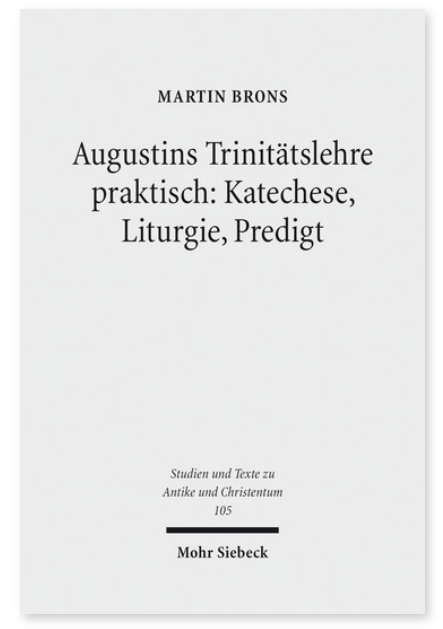

2017. XIV, 253 Seiten. STAC 105

ISBN 978-3-16-155394-3

DOI 10.1628/978-3-16-155394-3

eBook PDF 79,00€

ISBN 978-3-16-155393-6

fadengeheftete Broschur 79,00€
Wie vermittelt Augustin den trinitarischen Glauben in seiner kirchlichen Praxis? Martin Brons weist nach, dass der trinitarisch entfaltete Gottesglaube bei Augustin vom Erstkontakt eines Glaubensaspiranten mit der Kirche an eine Rolle spielt und eng mit Ritualen verknüpft ist. Diese spezifische Verbindung von Ritual und Unterweisung ermöglicht es Augustin, das trinitarische Heilsmysterium biographisch zu verorten sowie in Liturgie und Predigt kontinuierlich zu vertiefen. Dies wird besonders bei der Taufvorbereitung deutlich. Mithilfe der Ritual Studies gelingt es dem Autor, die fundamentale Bedeutung trinitätstheologischer Strukturen und Argumentationen und deren liturgische Kontextualisierung in den zentralen priesterlichen wie bischöflichen Aufgabenbereichen Augustins darzustellen und angemessen zu würdigen. Dadurch trägt er zu einem Verständnis des Kirchenvaters bei, das patristische, liturgiehistorische und systematische Fragestellungen integrativ berücksichtigt.

Martin Brons Geboren 1978; Studium der Theologie in Erlangen, Rom, Heidelberg und Berlin; Vikariat am Berliner Dom; Pfarrvikariat an der Erlöserkirche in Jerusalem; seit 2015 Pfarrer der Innenstadtgemeinde St. Egidien in Nürnberg. https://orcid.org/0000-0001-9275-6443

\section{Jetzt bestellen:}

https://mohrsiebeck.com/buch/augustins-trinitaetslehre-praktisch-katechese-liturgie-predigt-9783161553943?no_cache=1 order@mohrsiebeck.com

Telefon: $+49(0) 7071-923-17$

Telefax: $+49(0) 7071-51104$ 